\title{
Conflict handling Styles and Employees' Commitment at the Pharmaceutical Companies in Jordan
}

\author{
Bahjat Eid Al-jawazneh ${ }^{1}$ \\ ${ }^{1}$ Department of Business Administration, Faculty of Business \& Finance, Al-albayt University, Mafraq, Jordan \\ Correspondence: Bahjat Eid Al-jawazneh, Department of Business Administration, Faculty of Business \& \\ Finance, Al-albayt University, Mafraq, Jordan. E-mail: dr.jawazneh@gmail.com
}

Received: November 24, 2014

Accepted: February 4, 2015

Online Published: February 27, 2015

doi:10.5539/ijbm.v10n3p141

URL: http://dx.doi.org/10.5539/ijbm.v10n3p141

\begin{abstract}
This study aimed at studying the conflict handling styles impact on employees' affective, normative and continuance commitment, at the Pharmaceutical companies in Jordan, its population consisted of all the 14 Pharmaceutical companies in Jordan that are members of the Jordanian association of pharmaceutical manufacturers (JAPM).

The respondents to this research and unit of analysis were specified as all the managers who belong to different managerial levels. The rationale for choosing managers is that they have adequate knowledge to answer the study questionnaire and tend to provide unbiased answers.

The researcher applied (Rahim, 1983a) organizational Conflict Inventory-II (ROCI-II) to assess the conflict handling styles, and adopted (Meyer \& Allen, 1997). The employee commitment construct was to measure employees' commitment, 253 questionnaires were distributed, out of which 215 were retrieved, and 30 questionnaires did not meet the criteria of statistical analysis, therefore, only 185 were valid for conducting data analysis.

The results of the study have shown that conflict handling styles affect employees' affective, normative and continuance commitment at the Pharmaceutical companies in Jordan.
\end{abstract}

Keywords: conflict handling styles, employees' commitment, pharmaceutical industry

\section{Introduction}

The pharmaceutical industry is the second largest exporting industry in Jordan, representing $8 \%$ of the country's total exports during the period 2004 to 2008 , which included $84 \%$ human medication, thus contributing strongly in reducing the deficit in Jordan's trade balance (JKB Annual report, 2012). The sector became an export driven industry distributing its products in more than 60 countries due to its high quality, excellent reputation, and its affordable price. The pharmaceutical industry in Jordan is a pioneer exporting sector due to its high quality and excellent reputation. Therefore, $81 \%$ of production is exported to foreign markets. Jordan pharmaceuticals are now distributed worldwide in more than 60 countries and $90 \%$ of the exports are going to Arab countries. Jordan pharmaceutical companies have joint ventures and subsidiary companies in 8 Arab and foreign countries (JKB Annual report, 2012).

Like Many of today's organizations Pharmaceutical industry in Jordan fight for maintaining its competitive position in the marketplace, As a result of globalization and information and communications technologies that forced them to enter a new markets, adopt different operations strategies, and deal with different human cultures at work. Therefore, for these organizations, conflict handling and resolution is becoming a non-ending activity to meet the demands of the new wave of competitiveness.

On the other hand, the positive or negative performance of the human element at work is influenced by several factors that many scholars believe one of them can be the way organizations handle and manage conflict. Conflict is seen as a normal phenomenon and unavoidable process in any human centered atmosphere. But, what matters to most of us is the way it is being handled any managed.

According to Roloff (1987), "organizational conflict occurs when members engage in activities that are incompatible with those of colleagues within their network, members of other collectivities, or unaffiliated 
individuals who utilize the services or products of the organization", Thus, the effectiveness of individual employees, teams, departments and the entire organization, depends mainly on the management of their interpersonal conflict (Tjosvold, 1998).

Rahim (2002) wrote "What we need for today's organizations is conflict management and not conflict resolution. Conflict management does not necessarily imply avoidance, reduction, or termination of conflict. It involves designing effective macro-level strategies to minimize the dysfunctions of conflict and enhancing the constructive functions of conflict in order to enhance learning and effectiveness in an organization".

In the process of managing conflict, it is believed that the human element can be exposed to changes that may have an impact on his relationship with the organization, manifested by his level of commitment, which is according to William Kahn "the harnessing of organization members' selves to their work roles; in engagement, people employ and express themselves physically, cognitively, and emotionally during role performances" (Kahn, 1990).

Therefore, the researcher believes that building a thesis on the relationship between conflict handling behavior and organizational commitment is a timely one for industrial organizations operating in a developing country like Jordan since, employees cannot be committed to the organization whenever conflict exists (Nair, 2008). For this reason, conflicts must be handled with care to leave a positive impact on organizational commitment.

\section{Theoretical Background and Research Hypothesis}

For humans, conflict is considered to be an indicator for their existence and one measure of the degree of interaction with their daily life activities. In fact, a moderate amount of conflict, handled in a constructive manner, is essential for attaining and maintaining an optimum level of organizational effectiveness (Rahim \& Bonoma, 1979).

Conflict usually occurs when two or more social entities come in contact with one another in the process of goal attainment, their goals, their relationships may become incompatible or inconsistent. Relationships among such entities may become inconsistent when two or more of them desire a similar resource that is in short supply; when they have partially exclusive behavioral preferences regarding their joint action; or when they have different attitudes, values, beliefs, and skills ( Rahim, 2001). Conflict can even occur between individual, groups, organizations, and even nations (Rahim \& Bonoma, 1979; Rahim, 1983, 1986).

Managers viewed conflict management to be somewhat same level or greater importance than planning, communication, motivation or decision making (Thomas \& Schmidt, 1976). (Lippitt, 1982) went further to suggest that, organization should treat conflict management as an important management-development activity.

According to (Bisno, 1988) conflict is a process of social interaction involving a struggle over claims to resources, power and status, beliefs, and other preferences and desires. The aims of the parties in conflict may extend from simply attempting to gain acceptance of a preference, or securing a resource advantage, to the extremes of injuring or eliminating opponents, while Rahim (1983) created five conflict handling styles based on two dimensions. Concern for self and concern for others which project the motivational orientation of a given individual during conflict, the first dimension explains the degree to which a person attempts to satisfy his or her own concern by applying avoiding and dominating styles. The second dimension explains the degree to which a person wants to satisfy the concern for others through integrating, obliging and comprising styles.

Among the five conflict handling styles, the ones in which a moderate to high level of concern shown for the other part are considered as "cooperative conflict management styles". while the ones in which little concern is shown to the other party are considered as "uncooperative conflict management styles" (Rahim, Magner, \& Shapiro, 2000; Song, Xie, \& Dyer, 2000), as shown in Figure 1. 


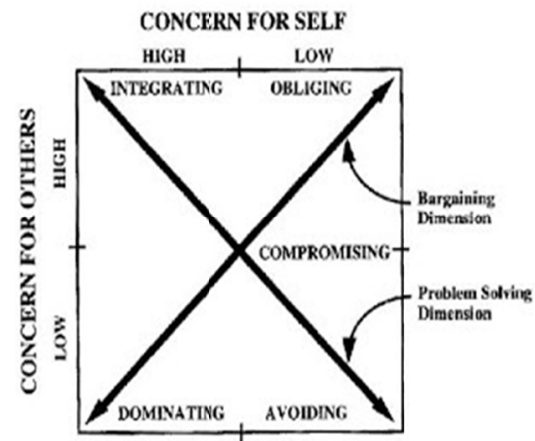

Figure 1. Cooperative conflict management styles

Source: Rahim, A. (2002).

Thomas and Kilman (1992) identified the five styles of conflict handling based on two dimensions of assertiveness and cooperativeness, which are: competing or confronting, accommodating, avoiding, collaborating and compromising. (Daniel Katz, 1965) introduced a typology that distinguishes three main sources of conflict: economic conflict, that involves competing motives to attain scarce resources, value conflict, which involves incompatibility in ways of life, the preferences, principles and practices that people believe in. and Power conflict occurs when each party wishes to maintain or maximize the amount of influence that it exerts in the relationship and the social setting.

Surveys have found that uncooperative conflict handling styles such as dominating and avoiding styles, which neglected the needs of others, is related to negative job performance (Ohbuchi \& Kitanaka, 1991). In addition, (Meyer, 2004) reported that when a manager increases the role of dominating trend of conflict management, the rate of accidents, absenteeism and overtime increase. (Mullins, 2005) stated that conflict is not necessarily a minus matter. If properly managed, it can deliver positive outcomes, It can be a source of energy for groups and for the organization. It can be insured as a constructive force and in certain circumstances it can be welcomed or even encouraged. Ahmad and Marinah, (2013) stated that the integrating style of conflict management plays a major function in enhancing commitment towards the establishment

On the other hand organizational commitment is defined by (Mowday et al., 1982), as a "strong belief in the organization's goals and values, a willingness to exert considerable effort on behalf of the organization, and a strong desire to remain a member of the organization". Bateman and Strasser (1984) defined it as "multidimensional in nature, involving an employee's loyalty to the organization, willingness to exert effort on behalf of the organization, degree of goal and value congruency with the organization, and desire to maintain membership". Glisson and Durick (1988), Meyer and Herscovitch (2001, p. 301) propose that commitment is "a force that binds an individual to a course of action of relevance to one or more targets". According to Allen and Meyer (1990), employees are expected to experience this force in the form of three bases: affective, normative, and continuance, which reflect emotional ties, perceived obligation, and perceived sunk costs in relation to a target, respectively, it also has been defined as the strength of an employee's involvement in an organization (Mowday, Porter, \& Steers, 1982).

One effective approach has been proposed by Mowday, Steers, and Porter (1979). It focuses on the emotional identification of employees with the organization. Commitment then originates from the individual desire to retain membership in the organization. The continuance perspective suggests that the satisfaction of an individual's needs and expectations in relation to financial rewards, status, and autonomy affects commitment. In other words, organizational commitment is a result of an individual evaluation of the benefits and costs associated with organizational membership (Herscovitch \& Meyer, 2002), (Mayer \& Allen, 1991) introduced the organizational commitment model which is composed of three components that are affective, normative and continuance. According to them, affective commitment (AC), refers to the employees' emotional attachment to, identification with, and involvement in the organization based on positive feelings or emotion towards the organization. The Mayer and Allen (1991) model also states that normative commitment (NC) is defined as an employee's feeling of responsibility to stay with the organization wherein it is based on the employee's having internalized with the values and goals of the organization and continuance commitment (CC) refers to an awareness of the costs linked with leaving the organization. 
Weiner and Vardi (1990) propose that the normative commitment is a result of culture and individual motivation. The culture or shared values in which employees are embedded can produce a sense of obligation or normative pressures. These pressures, in association with reward systems, can influence individual behavior toward commitment. The findings of the research by Meyer et al. (1993) showed that those employees with a strong affective commitment will remain with an organization because they want to, those with a strong continuance commitment remain because they have to, and those with a normative commitment remain because they feel that they have to. Meyer, Allen, and Smith (1993) say that the three types of commitment are a psychological state "that either characterizes the employee's relationship with the organization or has the implications to affect whether the employee will continue with the organization". As a matter of fact, individuals who are more committed are more likely to perform well, behave prosaically and less likely to leave (Kirkman \& Shapiro, 2001).

On the relationship between conflict and organizational outcome, conflict appears to be associated with negative emotional reactions such as anxiety, fear, mistrust, and resentment (Jehn, 1995), Mathieu and Zajac (1990) identified that there is a positive relationship between organizational commitment and job attendance and negative linear relevance to employee's lateness and turnover. Therefore, one who is obligated to a firm is more likely to remain at work. Commitment among employees can be strengthened by using integrating style because it would able to increase understanding between employees (Nizam, 2011).

Dobkin and Pace (2006) state that compromising style can boost commitment among Employees as it encourages the employees to work together to manage conflict between them. Compromising style gives team members a better understanding of the others in the team and as a result, it enhances commitment among employees towards the organization, (Green \& Marks, 2001).

Based on the previous literature the study hypotheses are following:

Ho1: There is no statistically significant impact of conflict handling styles on affective commitment at a significance level of $(\alpha \leq 0.05)$.

Ho2: There is no statistically significant impact of conflict handling styles on Normative commitment at a significance level of $(\alpha \leq 0.05)$.

Ho2: There is no statistically significant impact of conflict handling styles on Continuance commitment at a significance level of $(\alpha \leq 0$. 05).

\section{Statement of the Problem}

Businesses nowadays are operating in a turbulent environment where all types of business organizations are searching for measures that help them to improve their performance and therefore competitive, and one of which could be conflict handling to avoid negative consequences. conflict should not always be seen as something undesirable, but rather as a necessary outcome that can bring positive consequences if properly managed.

The transformation process of pharmaceuticals is very knowledge-intensive and thus provides an ideal setting for conflict at work, workplace conflict, which, if not managed effectively, leads to increased stress, reduced workplace performance, and negatively impacts health and the well-being of employees (McKenzie, 2002), while constructively managed conflict induces a positive performance (Albert, 2001). Mgbekem (2004) posited that some conflict positively affects the goal of the group of the organization and improve its performance. A collaborative conflict management culture is consistently associated with positive workplace performance and group level outcomes (Pruitt \& Camevale, 1993).

According to Deutsch (1973), conflict inevitably means that people are working against each other, in such a manner that what one wants is incompatible with that which another wants. It could bring about competition in the pursuit of goals. What the competitor gets comes at the expense of others, the job or program. It is therefore counterproductive, disruptive, unnatural and produces a deviation from the free flow of events. Therefore, this study aims to arrive at an answer for a debatable issue that links organizational conflict with the employees' commitment, thus the main research problem is:

Does conflict handling styles have an impact on employees' commitment at the Pharmaceutical companies in Jordan, which was subdivided into three sub-problems:

- What is the impact of conflict handling behavior on affective commitment.

- What is the impact of conflict handling behavior on normative commitment.

- What is the impact of conflict handling behavior on continuance commitment. 


\section{Objectives of the Study}

Organizational conflict is regarded as an ongoing human process in any organization, but its intensity and effect varies from one organization to another. Many academicians, researchers, and corporate people wrote about this important topic and gave their insight and suggested solutions on that matter, and related it to either social, human and organizational factors. Hence, the researcher is aiming here to enter into different social and work context, which is a Middle Eastern country such as the kingdom of Jordan, by trying to find out if conflict handling styles have an impact on employees' commitment.

\section{Research Model}

A different theory based models have been proposed to analyze the way in which individuals deal with and manage conflict. Taxonomies and meta taxonomies have been anticipated using a unidimensional approach of cooperation and competition styles (Deutsch, 1949; Tjosvold, 1998), a bidimensional approach involving four styles of conflict management behavior (Pruitt, 1983), a bidimensional approach involving five styles (Blake \& Mouton, 1964; Rahim \& Bonoma, 1979). After taking into consideration the Jordanian work environment, and the way the pharmaceutical industry operates, the researcher chose the five conflict handling styles proposed by (Rahim, 2002) and the employees' commitment construct of (Allen, et al., 1993).

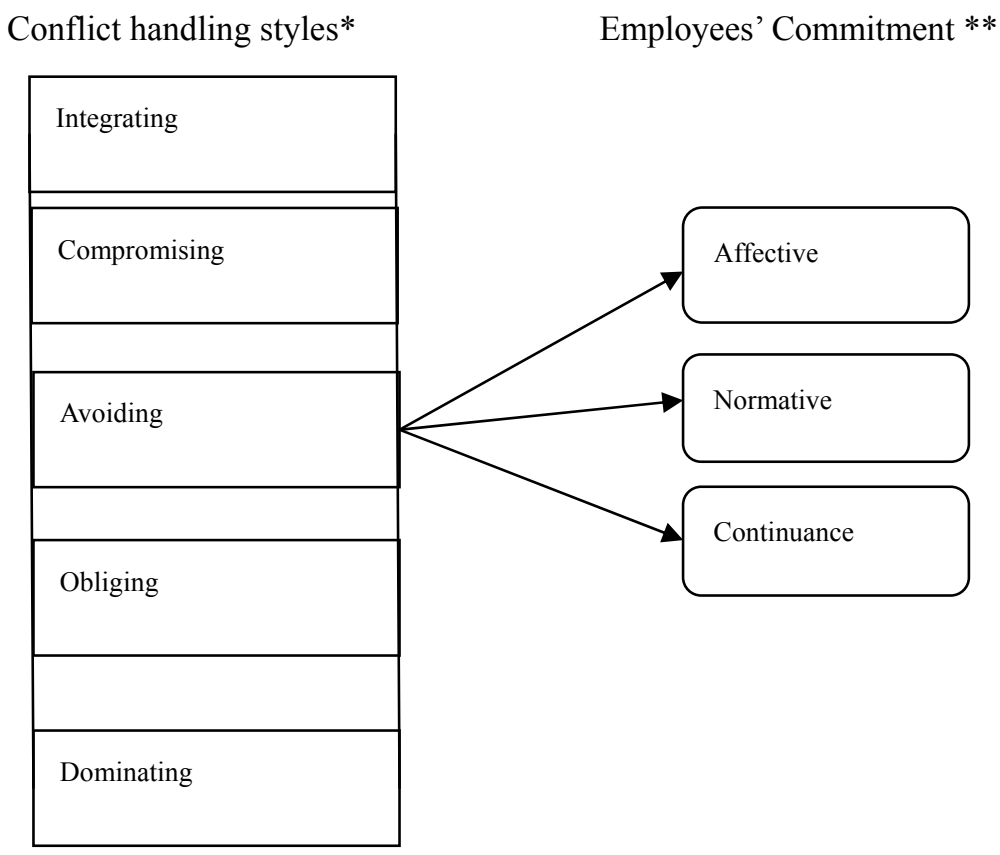

Figure 2. Research model

\section{Research Population and Sample}

The study population consists of all the 14 Pharmaceutical companies in Jordan that are members of the Jordanian Association of Pharmaceutical Manufacturers (JAPM). The respondents to this research and unit of analysis were specified as all the managers who belong to different managerial levels. The rationale for choosing managers is that they have adequate knowledge to answer the study questionnaire and tend to provide unbiased answers.

Out of the 14 manufacturing companies only 9 cooperated and agreed to be part of this study. Out of almost 400 hundred employees who occupy managerial and supervisory positions in these companies, the researcher accessed only 253 , and was able to retrieve 215 questionnaires, 30 of which were disqualified, therefore, 185 questionnaires were valid for conducting data analysis. Table 1 shows the characteristics of the study respondents. 
Table 1. Description of the study respondents

\begin{tabular}{|c|c|c|c|c|c|c|c|c|}
\hline \multicolumn{3}{|l|}{ Gender } & \multicolumn{3}{|c|}{ Experience in their current Job } & \multicolumn{3}{|c|}{ Educational Level } \\
\hline Class & Frequency & $\%$ & Class & Frequency & $\%$ & Class & Frequency & $\%$ \\
\hline Male & 136 & 73.5 & $\begin{array}{l}\text { Less than } 5 \\
\text { years }\end{array}$ & 15 & 8.1 & Diploma & 11 & 6 \\
\hline \multirow[t]{3}{*}{ Female } & 49 & 26.4 & $\begin{array}{l}\text { More than } \\
5 \text { less than } \\
10\end{array}$ & 67 & 36.2 & Bachelor & 123 & 66.4 \\
\hline & & & $\begin{array}{l}\text { More than } \\
10 \text { less } \\
\text { than } 15\end{array}$ & 84 & 45.4 & Master & 43 & 23.2 \\
\hline & & & $\begin{array}{l}\text { More than } \\
15\end{array}$ & 19 & 10.3 & Doctorate & 8 & 4.3 \\
\hline Total & 185 & 100 & & 185 & 100 & & 185 & 100 \\
\hline
\end{tabular}

\section{Research Instrument}

The researcher applied (Rahim, 1983a) organizational Conflict Inventory-II (ROCI-II) which is composed of 28 items, it is designed to measure five elements of the styles of handling conflict which is: Integrating (IN), Obliging (OB), Dominating (DO), Avoiding (AV), and Compromising (CO). To measure organizational commitment the (Meyer \& Allen, 1997) employee commitment construct was applied, it is composed of three dimensions: affective, normative, and continuance commitment.

\subsection{Face Validity}

The research instrument was examined and reviewed by different academicians who belong to different business schools here in Jordan, besides some expertise from the local Pharmaceutical industry had their inputs too, to make it sure the research instrument is fitted with the organizational environment in a country such as Jordan. Based on their feedback and suggestions some items were revised and others were discarded to make the instrument a valid one for such an environment.

\subsection{Internal Consistency}

The reliability of the research instrument was assessed by computing the Cronbach's Alpha Coefficient, which ranges from zero to one. The criterion that is used in the research to examine the reliability of each variable is that if the variable reliability is less than 0.60 , it is considered to be of poor reliability. If the variable reliability is over 0.70, it is considered as a reliable measure (Nunnally, 1978; Sekaran, 2003). Cronbach's alpha was calculated for all the variables that are included in the research model.

Table 2. The reliability test of the study variables

\begin{tabular}{lll}
\hline Variable & Number of Items & Alpha \\
\hline Integrating & 7 & 0.73 \\
Compromising & 4 & 0.81 \\
Avoiding & 6 & 0.87 \\
Obliging & 6 & 0.69 \\
Dominating & 5 & 0.92 \\
Affective & 6 & 0.88 \\
Continuance & 7 & 0.76 \\
Normative & 6 & 0.79 \\
\hline
\end{tabular}

\section{The Statistical Tools Employed in This Study}

- Frequencies and percentages to describe the respondents of the study.

- Cronbach Alpha to test the internal consistency of the study instrument.

- Multiple regression analysis to test the impact conflict handling styles on employees' commitment.

\section{Results of Hypothesis Test}

To test the hypothesis, the following rule was applied; if the significance value (P-value) $\leq 0.05$, the null 
hypothesis (H0) will be rejected, therefore the alternative hypothesis (H1) will be accepted, the followings are the results of the hypothesis test:

Ho1: There is no statistically significant impact of conflict handling styles on affective commitment at a significance level of $(\alpha \leq 0$. 05).

Table 3. The results multiple regression test of the impact of conflict handling styles on affective commitment

\begin{tabular}{lllll}
\hline Conflict Handling Styles & $\beta$ value & Beta value & Calculated t-value & P-value \\
\hline Integrating & 0.349 & 0.255 & 3.000 & 0.003 \\
Compromising & 0.223 & 0.176 & 2.752 & 0.007 \\
Avoiding & 0.258 & 0.216 & 3.21 & 0.002 \\
Obliging & 0.189 & 0.258 & 3.94 & 0.000 \\
Dominating & 0.155 & 0.172 & 2.79 & 0.006 \\
0.404 & & & & $R^{2}$ value \\
17.171 & & & F value \\
0.000 & & & P-value \\
\hline
\end{tabular}

The results in table 3 show that, the squared coefficient of correlation is $(0.404)$, which explains $(40.4 \%)$ of the impact of conflict handling styles on affective commitment, the table above also shows the calculated F-value is (17.171), and the probabilistic value P-value is (0.000). Therefore, the null hypothesis is rejected since the p-value is $\leq 0.05$, and the alternative hypothesis $\mathrm{H} 1$ is accepted, which means conflict handling styles have an impact on affective commitment.

Table 3 shows also, the impact of each dimension of conflict handling styles on affective commitment. The integrating style of conflict handling styles has a positive impact on affective commitment with a $\beta$ value of 0.349 , which is statistically significant since the $P$-value $\leq 0.05$ and $t=3.00$. The compromising dimension left an impact on affective commitment with a $\beta$ value of 0.223 which statistically significant since the $P$-value $\leq 0.05$ and $\mathrm{t}=2.752$, avoiding style had its share of the impact on affective commitment with a $\beta$ value of 0.258 , which statistically significant since the P-value $\leq 0.05$ and $t=3.21$. The obliging style has an impact on affective commitment with a $\beta$ value of 0.189 which statistically significant since the $P$-value $\leq 0.05$ and $t=3.94$, and lastly, the dominating style of conflict handling styles impacted positively the affective commitment with a $\beta$ value of 0.155 which statistically significant since the $\mathrm{P}$-value $\leq 0.05$ and $\mathrm{t}=2.79$.

Ho2: There is no statistically significant impact of conflict handling styles on Normative commitment at a significance level of $(\alpha \leq 0.05)$.

Table 4. The results multiple regression test of the impact of conflict handling styles on normative commitment

\begin{tabular}{lllll}
\hline Conflict handling styles & $\beta$ value & Beta value & Calculated t-value & P-value \\
\hline Integrating & 0.542 & 0.349 & 4.912 & 0.000 \\
Compromising & 0.075 & 0.051 & 0.988 & 0.324 \\
Avoiding & 0.326 & 0.162 & 2.66 & 0.009 \\
Obliging & 0.237 & 0.288 & 5.29 & 0.000 \\
Dominating & 0.398 & 0.389 & 7.66 & 0.000 \\
0.61 & & & & $R^{2}$ value \\
35.28 & & & & F value \\
0.000 & & & & P-value \\
\hline
\end{tabular}

Table 4 shows that, the squared coefficient of correlation is $(0.61)$, which explains $(61 \%)$ of the impact of conflict handling styles on Normative commitment, it also shows the calculated F-value is (35.28), and the probabilistic value P-value is (0.000). Therefore, the null hypothesis is rejected since the p-value is $\leq 0.05$, and the alternative hypothesis $\mathrm{H} 1$ is accepted, which means conflict handling styles have an impact on Normative commitment.

Table 4 shows also, the impact of each dimension of conflict handling styles on Normative commitment, the integrating style of conflict handling styles has a positive impact on Normative commitment with a $\beta$ value of 0.542 which is Statistically significant since the P-value $\leq 0.05$ and $t=4.912$, the compromising dimension has 
an impact on Normative commitment with a $\beta$ value of 0.075 which is statistically significant since the P-value $\leq 0.05$ and $\mathrm{t}=0.988$, avoiding style got an impact on Normative commitment with a $\beta$ value of 0.326 which is statistically significant since the P-value $\leq 0.05$ and $t=2.66$, the obliging style has an impact on Normative commitment with a $\beta$ value of 0.237 which statistically significant and a $P$-value $\leq 0.05$ and $t=5.29$, and finally, the dominating style of conflict management positively impacted the Normative commitment with a $\beta$ value of 0.398 which statistically significant since the $\mathrm{P}$-value $\leq 0.05$ and $\mathrm{t}=7.66$.

Ho3: There is no statistically significant impact of conflict handling styles on Continuance commitment at a significance level of $(\alpha \leq 0.05)$.

Table 5. The results multiple regression test of the impact of conflict handling styles on continuance commitment

\begin{tabular}{lllll}
\hline Conflict handling styles & $\beta$ value & Beta value & Calculated t-value & P-value \\
\hline Integrating & 0.542 & 0.344 & 4.712 & 0.000 \\
Compromising & 0.082 & 0.054 & 1.008 & 0.324 \\
Avoiding & 0.320 & 0.155 & 2.498 & 0.009 \\
Obliging & 0.231 & 0.270 & 4.88 & 0.000 \\
Dominating & 0.408 & 0.389 & 7.53 & 0.000 \\
0.573 & & & & $R^{2}$ value \\
36.21 & & & F value \\
0.000 & & & P-value \\
\hline
\end{tabular}

The results in table 5 show that, the squared coefficient of correlation is $(0.573)$, which explains $(573 \%)$ of the impact of conflict handling styles on continuance commitment, the table above shows the calculated F-value is (36.21), and the probabilistic value P-value is (0.000). Therefore, the null hypothesis is rejected since the p-value is $\leq 0.05$, and the alternative hypothesis $\mathrm{H} 1$ is accepted, which means conflict handling styles have an impact on continuance commitment.

Table 5 shows also, the impact of each dimension of conflict handling styles on continuance commitment, the integrating style of conflict handling styles has a positive impact on continuance commitment with a $\beta$ value of 0.542 which is statistically significant since the $P$-value $\leq 0.05$ and $t=4.712$, the compromising dimension left an impact on continuance commitment with a $\beta$ value of 0.0 .082 which is statistically significant since the P-value $\leq 0.05$ and $\mathrm{t}=1.008$, avoiding style had its share of the impact on continuance commitment with a $\beta$ value of 0.320 which statistically significant since the $P$-value $\leq 0.05$ and $t=2.498$, the obliging style has an impact on continuance commitment with a $\beta$ value of 0.231 which statistically significant since the $P$-value $\leq 0.05$ and $t=$ 4.88 , and lastly, the dominating style of conflict impacted positively continuance commitment with a $\beta$ value of 0.408 which is statistically significant since the $P$-value $\leq 0.05$ and $t=7.53$.

\section{Results Discussion and Conclusion}

The results of the study have shown how conflict handling styles affect employees' commitment at the Pharmaceutical companies in Jordan, these major results are consistent with the study of (Dobkin \& Pace, 2006) and (Green \& Marks, 2001). This can be understood, because committed employees need to work in an environment where their efforts are coupled with less psychological burden, and more positive human interactions, though it is true that conflict is part of our organizational routine, but the way it is being handled and carried makes it either boon or bane to organizations.

The impact of integrating style on each dimension of employees' commitment, signifies that, Pharmaceautical companies face complex issues which are in need of ideas to come up with better alternatives for better solutions. Thus, Commitment is needed from other parties for successful implementation, to apply integrative style of conflict management effectively, enough Time and resources are needed for problem solving and aggregation, and that is in line with what (Pruitt \& Camevale, 1993; Ahmad \& Marinah, 2013; Nizam, 2011).

Obliging style on the other hand, means respondents may believe that they may be wrong, but the issue is more important to the other party. They willing to give up something in exchange for something from the other party in the future, but still they are dealing from a position of weakness. Hence, preserving relationship is important to maintain an acceptable level of employees' commitment, which may be viewed as a result of an individual evaluation of the benefits and costs associated with organizational membership (Herscovitch \& Meyer, 2002).

Dominating style is possibly urgent, when the situation is trivial and Subordinates lack expertise to make 
technical decisions. Then speedy and swift decision is badly needed, that may lead to the implementation of unpopular course of action to overcome the high cost of the unfavorable decision by the other party. But its positive impact on commitment can be due to the satisfaction of an individual's needs and expectations in relation to financial rewards, status, and autonomy (Herscovitch \& Meyer, 2002).

When confronting the other party outweighs benefits of resolution, avoiding conflict handling styles may be the right thing to do. Pharmaceutical industry in Jordan cannot be spared from such situation where avoidance style become necessary measure to overcome some obstacles that the sector faces from time to time, in spite of that employees' commitment remains unshaken, and that is probably due to their deep understanding of such situation, this contradicts what (Jehn, 1995) concluded.

Scholars such as, (Dobkin \& Pace, 2006) and (Green \& Marks, 2001) agree: compromising style gives team members a better understanding of the others in the team and as a result. It enhances commitment among employees towards the organization, specially when goals of parties are mutually exclusive and parties are equally powerful, Consensus cannot be reached, integrating or dominating style is not successful, then reaching compromise with other members in the organization can be a temporary solution.

\section{References}

Ahmad, A. R., \& Marinah, A. (2013). Learning organization and organizational commitment in primary school. International Proceedings of Economics Development and Research, 60(12).

Albert, I. O. (2001). Introduction to Third Party Intervention in Community conflicts. John Archers Publishers Limited.

Allen, N. J., \& Meyer, J. P. (1990). The Measurement and Antecedents of Affective. Continuance and Normative Commitment to the Organization. Journal of Occupational Psychology, 63, 1-18. http://dx.doi.org/10.1111/j.2044-8325.1990.tb00506.x

Bateman, T. S., \& Strasser, S. (1984). A longitudinal analysis of the antecedents of Antecedents, correlates, and consequences. Journal of Vocational Behavior, 61, 20-52.

Bison, H. (1988). Managing conflict. Newbury Park, CA: Sage.

Blake, R. R., \& Mouton, J. S. (1964). The managerial grid. Houston, TX: Gulf.

Deutsch, M. (1949). A theory of cooperation and competition. Human Relations, 2, 129-151. http://dx.doi.org/10.1177/001872674900200204

Deutsch, M. (1973). The resolution of conflict. New Haven: C.T. Yale University Press.

Dobkin, A., \& Pace, C. (2006). Communication in a changing world: An introduction to theory and practice. New York: McGraw Hill.

Glisson, C., \& Durick, M. (1988). Predictors of job satisfaction and organiza- tional commitment in human service organizations. Administrative Science Quarterly, 33, 61-81. http://dx.doi.org/10.2307/2392855

Gordon, L. (1982). Management Development as the Key to Organisation Renewal. Journal of Management Development, 1(2), 34-40. http://dx.doi.org/10.1108/eb051520

Green, B., \& Marks, M. (2001). Maximizing the benefits of task conflict: The role of conflict management. International Journal of Conflict Management, 12(1), 4-22. http://dx.doi.org/10.1108/eb022847

Jehn, K. (1995). A multimethod examination of the benefits and detriments on intragroup conflict. Administrative Science Quarterly, 40, 256-282. http://dx.doi.org/10.2307/2393638

Kahn, W. A. (1990). Psychological conditions of personal engagement and disengagement at work. Academy of Management Journal, 33, 692-724. http://dx.doi.org/10.2307/256287

Katz, D. (1965). Nationalism and strategies of international conflict resolution.

Kelman. (1965). International behavior: A social psychological analysis. New York: Holt, Rinehart \& Winston.

Kirkman, B., \& Shapiro, D. (2001). The impact of cultural values on job satisfaction and organizational commitment in self-managing work teams: The mediating roles of employee resistance. Academy of Management Journal, 44, 557-569. http://dx.doi.org/10.2307/3069370

Meyer, J. P., \& Allen, N. J. (1991). A three-component conceptualization of organizational commitment. Human Resource Management Review, 1(1), 61-98. http://dx.doi.org/10.1016/1053-4822(91)90011-Z

Meyer, J. P., \& Herscovitch, L. (2001). Commitment in the Workplace: Toward a General Model. Human 
Resource Management Review, 11, 299-326. http://dx.doi.org/10.1016/S1053-4822(00)00053-X

Meyer, J. P., Allen, N. J., \& Smith, C. A. (1993). Commitment to organizations and occupations: Extension and test of a three-component model. Journal of Applied Psychology, 78, 538-551. http://dx.doi.org/10.1037/0021-9010.78.4.538

Meyer, J. P., Stanley, D. J., Herscovitch, L., \& Topolnytsky, L. (2002). Affective, Continuance, and normative commitment to organization: A meta-analysis of Organizational commitment. Academy of Management Journal, 27, 95-112.

Meyer, J., \& Allen, N. (1997). Commitment in the Workplace: Theory, Research, and Application. Sage Publications.

Meyer, S. (2004). Organizational response to conflict: Future conflict and work outcomes. Social Work Research, 28, 183-190. http://dx.doi.org/10.1093/swr/28.3.183

Mgbekem, S. J. (2004). Management of University Education in Nigeria. Calabar: University Of Calabar Press.

Mowday, R. T., Porter, L. W., \& Steers, R. M. (1982). Organizational linkages: The psychology of commitment, absenteeism, and turnover. San Diego, CA: Academic Press.

Mowday, R. T., Steers, R. M., \& Porter, L. W. (1979). The measurement of organizational commitment. Journal of Vocational Behavior, 14, 224-247. http://dx.doi.org/10.1016/0001-8791(79)90072-1

Mullins, L. J. (2005). Management and Organisational Behaviour. Pearson Education Limited, England.

Nair, N. (2008). Towards understanding the role of emotions in conflict: A review and future directions. $\begin{array}{llll}\text { International Journal of Conflict } & \text { Management, }\end{array}$ http://dx.doi.org/10.1108/10444060810909301

Nizam. A. M. Y. (2011). Conflict management: Evaluation in handling conflict communication in the organization. 2nd International Conference on Business and Economic Research (2nd ICBER 2011) Proceeding.

Ohbuchi, K., \& Kitanaka, T. (1991). Effectiveness of power strategies in interpersonal conflict among Japanese students. Journal of Social Psychology, 131, 791-805. http://dx.doi.org/10.1080/00224545.1991.9924666

Pruitt, D. G. (1983). Strategic choice in negotiation. American al Scientist, 27, 167-194. http://dx.doi.org/10.1177/000276483027002005

Pruitt, D. G., \& Carnival, P. J. (1993). Negotiation in social conflict. Buckingham, England: Open. University Press.

Rahim, M. A. (1983). A Measure of Styles of Handling Interpersonal Conflict. Academy of Management Journal, 26, 368-376. http://dx.doi.org/10.2307/255985

Rahim, M. A. (1986). Referent Role and Styles of Handling Interpersonal Conflict. Journal of Social Psychology, 126, 79-86. http://dx.doi.org/10.1080/00224545.1986.9713573

Rahim, M. A. (2001). Managing Organizational Conflict (3rd ed.). Quorum Books.

Rahim, M. A. (2002). Toward A theory of Managing organizational conflict. The International Journal of Conflict Management, 13(3), 206-235. http://dx.doi.org/10.1108/eb022874

Rahim, M. A., \& Bonoma, T. V. (1979). Managing organizational conflict: A model for diagnosis and intervention. Psychological Reports, 44, 1323-1344. http://dx.doi.org/10.2466/pr0.1979.44.3c.1323

Rahim, M. A., Magner, N. R., \& Shapiro, D. L. (2000). Do justice perceptions influence styles of handling conflict with supervisors? What are justice perceptions, precisely? The International Journal of Conflict Management, 11, 9-31. http://dx.doi.org/10.1108/eb022833

Roloff, M. E. (1987). Communication and conflict. In C. R. Berger \& S. H. Chaffee (Eds.), Handbook of communication science (pp. 484-534). Newbury Park, CA: Sage.

Song, X. M., Xie, J., \& Dyer, B. (2000). Antecedents and consequences of marketing managers' conflict-handling behaviors. Journal of Marketing, 64, 50-66. http://dx.doi.org/10.1509/jmkg.64.1.50.17989

The Jordan Kuwaiti Bank Annual Report. (2012). Pharmaceutical Industry in Jordan: The psychology of commitment, absenteeism, and turnover. San Diego, CA: Academic Press.

Thomas, K. W., \& Kilmann, R. H. (1974). Thomas-Kilmann Conflict Mode Instrument. Tuxedo, New York, NY. 
Thomas, K. W., \& Schmidt, W. H. (1976). A Survey of Managerial Interests with Respect to Conflict. Academy of Management Journal, 19, 315-318. http://dx.doi.org/10.2307/255781

Tjosvold, D. (1998). Cooperative and competitive goal approach to conflict: accomplishments and challenges. Applied Psychology: An International
Review,
47 , 285-332. http://dx.doi.org/10.1111/j.1464-0597.1998.tb00025.x

Weiner, Y., \& Vardi, Y. (1990). Relationships between organizational culture and individual motivation: A conceptual integration. Psychological Reports, 67, 295-306. http://dx.doi.org/10.2466/pr0.1990.67.1.295

\section{Copyrights}

Copyright for this article is retained by the author(s), with first publication rights granted to the journal.

This is an open-access article distributed under the terms and conditions of the Creative Commons Attribution license (http://creativecommons.org/licenses/by/3.0/). 